\title{
A systematic review of the literature comparing male non-serial sexual killers and sexual aggressors: examining homogeneous and heterogeneous characteristics of these groups
}

\author{
E. B. Stefanska ${ }^{a}$, A. R. Beech ${ }^{a}$ and A. J. Carter ${ }^{b}$
}

${ }^{a}$ School of Psychology, University of Birmingham, Birmingham, UK; ${ }^{b}$ National Offender Management Service,

London, UK

15 June 2015

This review explores the current state of knowledge about sexual homicide, which is often based on uncertainties and contradictory assumptions. In the introduction we examine some of the methodological issues, such as low prevalence rates and operationalisation problems, that contribute to the situation regarding the existing knowledge base. The research investigating the key types of sexual homicide and the possible characteristics distinguishing sexual killers from others types of sexual offenders are outlined in order to provide the reader with the background to the aims of this systematic review. Additionally, throughout the paper, we go back to the various methodological complications so that in the method section of this review we can note the ways researchers have tried to overcome them.

While there are issues that make compiling accurate figures challenging (see later), the studies looking at the prevalence of sexual killing consistently show that it is a relatively rare phenomenon with estimates ranging from approximately $6 \%$ of all homicides in the UK (Beech, Fisher, \& Ward, 2005) to $4 \%$ of homicides in Canada (Roberts \& Grossman, 1993) and $1 \%$ of homicides in the USA (Chan \& Heide, 2009). Further, it seems that in North America, the number of homicides assessed as sexual in nature has been declining (James \& Proulx, 2014). Although estimated to be rare, the statistics from the UK note that in June 2012 in the UK there were 6320 men serving a conviction for murder or manslaughter, and 840 of these men killed with an apparent or admitted sexual

element (Planning and Analysis Group, National Offender Management Service, NOMS, personal communication, August 2013). This means that out of all men detained for murder or manslaughter in the UK prison population, $13.3 \%$ are assessed as sexual murderers and this number represents an increase from the May 2003 estimate of 6\% (Beech et al., 2005).

The topic of sexual homicide has been extensively examined for the last two decades (Chan \& Heide, 2009). Despite this examination, the many methodological complications encountered by researchers, as discussed in this review, hamper our ability to better understand and draw conclusions about this crime and its perpetrators. Specifically, both the low prevalence rates noted above and the difficulties in accessing detailed descriptions of the offense inevitably mean that small sample sizes are usually used in studies (Porter, Woodworth, Earle, Drugge, \& Boer, 2003). Accounting for the different role that killing can play in relation to sexual behaviour could help to improve our understanding of this crime (Stefanska, Carter, Higgs, Bishopp, \& Beech, 2015). It is worth noting that while the term sexual killing, murder and homicide tend to be used interchangeably, they generally encompass cases of murder, manslaughter as well as cases of diminished responsibility, with or without a hospital order. 
Operationalisation of the term "sexual killing" is a problem since sexual homicide does not exist as a distinct offence in the USA, Canada, the UK and Germany where much of the research on sexual killing originates (James \& Proulx, 2014; Oliver, Beech, Fisher, \& Beckett, 2007) and different definitions have been used for research purposes. For example, Ressler, Burgess, and Douglas (1988) defined sexual homicide as "murder with evidence or observations that indicate(s) that the murder was sexual in nature" (p. 13), Porter et al. (2003) classified their samples as sexual homicide if there was "physical evidence of sexual activity with the victim before, during, or after the homicide" (p. 463), while Beech et al. (2005) looked at whether there was "clear forensic evidence of a sexual element to the killing, or a sexual component [was] admitted or suspected" (p. 5). Although an extensive review of the definitions used in different studies reveals that, in order to be classified as sexual, some type of physical evidence for sexual activity must usually be present, the lack of such evidence does not necessarily exclude cases such as those for which the motivation can be labelled as sexual (Kerr, Beech, \& Murphy, 2013). In addition, the absence of a legal or mental health label (it is not recognised as a specific paraphilia) makes identification of these cases for research purposes even harder (Schlesinger, 2004).

Schlesinger (2004) argued that the classification process is not always straightforward as applying criteria too literally (e.g. by taking into account only physical evidence) can also lead to error, given that many seemingly sexual murders may not be sexually motivated. At the same time, establishing whether a killing should be classified as sexual when a sexual element is not easily recognisable is similarly difficult (Beech et al., 2005). These issues aside, motivation in sexual homicide has attracted a great deal of attention from scholars, which has ultimately led to several typologies of sexual homicide being proposed based on motivation, and general offending patterns (Maniglio, 2010).

Two types of sexual killers, angry and sadistic, have consistently been reported (Proulx, 2008). A third category of sexual killers who commit homicide in order to eliminate witnesses of a sexual assault has also been identified in the literature (e.g. Beech et al., 2005) but its conclusion has been disputed. Folino (2000) suggests that cases where a victim is killed in order to avoid detection should be considered as false positives in the classification system and thus should be excluded from sexual homicide numbers.

Of note is that many (especially) early studies included both serial killers and non-serial offenders in their samples. Serial offenders are generally defined as perpetrating against two or more victims. Nonserial offenders are defined as killing one or two victims without an emotional cooling-off period. Nonserial offending is considered to be two victims killed at the same time or closely together without opportunity for reflection (Proulx, Cusson, \& Beauregard, 2007). Although studies have included both serial and non-serial offenders, a study by Campos and Cusson (2007) noted differences in various psychological and crime characteristics between serial and non-serial sexual killers. A recent systematic review further revealed that serial and non-serial killers tend to have 
two distinct profiles (James \& Proulx, 2014). Although it could be argued that drawing cases (non-serial sexual killers) and the comparison cases (serial sexual killers) from different sources limits comparability (Kopec \& Esdaile, 1990), academics have suggested that due to sufficient differences between the groups future studies should distinguish between serial and non-serial offenders (Carter \& Hollin, 2010; James \& Proulx, 2014). Unfortunately, many early sexual homicide studies not only combined the two groups but comprised samples that were often overrepresented by serial killing.

The search for a better understanding of the phenomenon of sexual murder has led scholars to investigate whether sexual killers have any distinctive characteristics that distinguish them from other offenders. One of the earliest studies using this approach was by Langevin, Ben-Aron, Wright, Marchese, and Handy (1988), who compared sexual killers to both a group of non-sexual killers and a group of sexual aggressors (namely rape or attempted rape). Later studies largely omitted the nonsexual homicide group and concentrated on a comparison between sexual killers and sexual aggressors. One of the reasons for this could be an attempt to determine whether sexual killers and sexual aggressors should be considered as one or two separate groups of sexual offenders (Proulx et al., 2007; Salfati \& Taylor, 2006).

Overall, various background and developmental factors as well as personality characteristics have been used to compare sexual killers and sexual aggressors. Different criminal and offence (situational) variables have also been considered. Surprisingly, many studies have looked at the different types of sexual offenders in isolation and only a few have actually directly compared the groups (Vettor, Beech, \& Woodham, 2014) although it could be argued that studies without a control group in their design have limited comparability because the samples are not constructed in the same fashion. Different studies directly comparing sexual killers and sexual aggressors have looked at different variables, leading to further difficulties in drawing comparisons. Studies have tended to combine perpetrators of women, children and men in their samples disregarding a possibility that these may be different types of sexual killers (Proulx et al., 2007). Despite these problems, many authors conclude that overall the groups have more similarities than differences (Chan \& Heide, 2009; Nicole \& Proulx, 2007; Oliver et al., 2007; Proulx \& Sauvêtre, 2007) leading some to suggest that the offence should not be viewed as separate. That is, they should be viewed as occurring at different points on a continuum with circumstantial violence determining the fatal outcome (Oliver et al., 2007; Proulx et al., 2007; Salfati \& Taylor, 2006). Despite this claim, methodological issues of studies on which this premise is based have rarely been considered and compared. Therefore, the current study aims to review what is known about the characteristics of sexual killers and sexual aggressors, by systematically looking only at the studies that directly compare the groups (i.e. have similarly constructed samples). Here some conclusions can be drawn as to which characteristics have consistently been shown to be homogeneous (i.e. similar across the two groups) and which appear to be heterogeneous (i.e. different and more prevalent for one group).

\section{Method}

The search process and strategy, inclusion and exclusion criteria, data extraction, assessment of study quality as well as data synthesis followed the guidelines for systematic reviews recommended by Pretticrew and Roberts (2006).

\section{Data sources}

A scoping exercise provided an initial indication of the quantity of potentially relevant studies. An electronic search of the Cochrane Library was performed in order to identify any existing systematic reviews focusing on a similar topic. No relevant work was found. In addition, five electronic platforms (EBSCO, Ovid, ProQuest, Science Direct, and Thomson Reuters) were searched for articles published between January 1985 and December 2014. The platforms included the following databases: Academic 
Search Complete, Arts \& Human Citation Index, Criminal Justice Abstract, MEDLINE, ProQuest Dissertations \& Theses: UK \& Ireland, PsycINFO, PsycARTICLES, Science Citation Index, Science Citation Index Expanded, Science Direct, Social Sciences and Humanities, Web of Science. Separate searches were conducted for the keywords sex offences or offender(s) combined with the following: murder(s); murderer(s); homicide(s); killing(s); killer(s) and manslaughter(s). Depending on the database, the search method consisted of searching the title and/or abstract and/or topic using the wildcard searches: sex* offend* AND murder* or homicide* or kill* or manslaughter*. Further papers were identified by manually searching the reference list of retrieved articles. The search was not restricted to peer-reviewed journals, that is, book chapters written by the experts in the field were included but newspaper and magazine articles were excluded.

\section{Inclusion/exclusion criteria}

Studies were included if they: (1) examined similarities and differences between sexual killers and sexual aggressors; (2) compared adult, male offenders; (3) relied on the samples of offenders who perpetrated predominantly against pubescent female victims and (4) the sexual homicide sample was mainly non-serial. Restricting the sample based on these characteristics follows the method used in previous research (Carter \& Hollin, 2010). Narrative reviews, editorials and commentaries were not included. We rejected any studies that looked at female, mixed (females and males) and juvenile perpetrators as well as studies looking only at victim characteristics. Studies where the sexual homicide group consisted of predominantly multiple-victim (serial) offenders (or when this was not specified) were rejected (although, when possible, authors were approached for clarification of their sample selection criteria). This exclusion was applied because sufficient discrepancies were found to exist between non-serial and serial sexual killers with non-serial cases representing a more polymorphic group of criminals (James \& Proulx, 2014). The sexual aggressor group would also be expected to be a more polymorphic group of criminals making non-serial killers a more appropriate comparison group. Studies not published entirely in English were also not included.

\section{Study selection}

Electronic searches identified a total of 825 articles ( 289 from Ebsco, 248 from Ovid, 80 from ProQuest, 45 from Science Direct and 163 from Thomson Reuters). A total of 203 duplicates were removed. Titles and abstracts were considered individually and articles unrelated to the current question were disqualified (total of 589). The remaining 33 articles were subjected to the inclusion and exclusion criteria. In addition, the reference lists of included articles were searched in order to identify potentially relevant studies. This additional search identified one study, which was also assessed using the inclusion and exclusion criteria (Figure 1). In all, 10 studies were included in this systematic review: as follows, in order of publication: Grubin (1994), Milsom, Beech, and Webster (2003), Salfati and Taylor (2006), Chéné and Cusson (2007), Nicole and Proulx (2007), Oliver et al. (2007), Proulx and Sauvêtre (2007), Healey, Lussier, and Beauregard (2013), Vettor et al. (2014) and Higgs, Carter, Stefanska, and Glorney (2015).

\section{Quality assessment}

To assess the literature for methodological rigour, a checklist adapted from the Critical Appraisal Skills Program (National Health Service, 2013) was developed. Since the inclusion/exclusion criteria aimed to search for comparative studies and because the samples were selected based on the conviction criteria, not surprisingly all of the studies retrieved were case-control in their design. Therefore, potential confounders as well as selection and measurement biases in case-control studies, reviewed by 


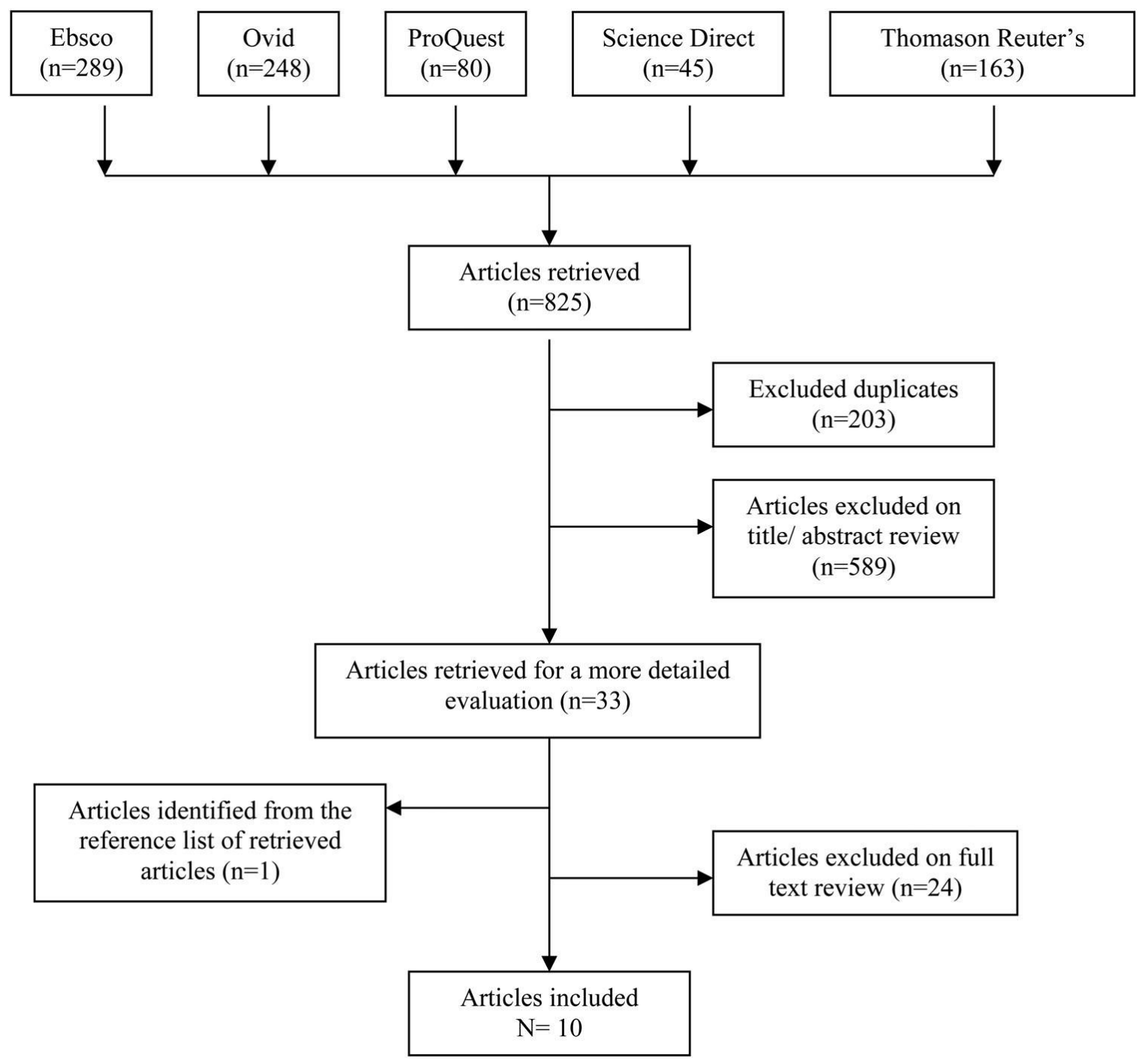

Figure 1. Summary of the selection process.

Kopec and Esdaile (1990), were taken into consideration. The included studies were assessed in relation to the following criteria: (1) selection bias (reliable and appropriate system for selecting cases, sufficient number of cases); (2) measurement or classification bias (criteria eligibility, measurement procedures) and (3) outcome (comparability of the groups and authors' consideration of confounding factors). Two points were assigned when the criteria were met, one point if the criteria were sufficiently/partially met and no points if the criteria were either not met or this part of design was not reported. The same assessment checklist was applied to both qualitative and quantitative studies. The score was converted to a percentage rather than an absolute value to take account of the fact that some questions were not applicable to the qualitative studies. On this basis, each study was subsequently assigned a rating of "good quality" (score of 100-70\%), "fair quality" (69-30\%) and "poor quality" (0-29\%).

\section{Data extraction}

The following data were extracted: study characteristics; sample details; methods; key findings (differences and similarities); authors' conclusions; and reported strengths and weaknesses of the study. The key differences and similarities identified from the results of all 10 studies were further ascribed to central themes and synchronicity was achieved through a process of clustering (Braun \& Clarke, 2006). 
Results

Three studies (Chéné \& Cusson, 2007; Nicole \& Proulx, 2007; Proulx \& Sauvêtre, 2007) used the same data set, although due to missing data, 10 sexual killer cases were excluded in the Proulx and Sauvêtre (2007) study. By way of contrast, a study by Chéné and Cusson (2007) applied different inclusion criteria and retained cases of intrafamilial assault, which resulted in the inclusion of more cases. A study by Healey et al. (2013) used Proulx and colleagues' sample as well as additional cases previously not reported (E. Beauregard, personal communication, 2015). Vettor et al. (2014) used a sample of the original STEP 4 study by Beech and colleagues, which was reported by Oliver et al. (2007). There was also a considerable overlap between Milsom et al., (2003) and Oliver et al., (2007) samples, as the offenders interviewed were housed in the same prison. This means that approximately 300 sexual killers were compared in total, although the exact number is not known due to the sample overlaps noted. Regarding the overlaps, it should be noted that: (a) the studies using the same samples examined different variables; (b) some studies using an overlapping sample of sexual killers used a different sample of sexual aggressors and (c) it is not possible to establish the exact number of the overlap due to the cases being anonymous. On quality assessment, all studies were assessed to be of good quality.

Drawing data from particular types of institutions may have led to the over or underrepresentation of certain factors, although this did not affect comparability. To avoid possible confounding effects, the studies by Healey et al. (2013) and Higgs et al. (2015) additionally matched their samples on various sociodemographic variables. The self-disclosure nature of some designs (e.g. data collected at the stage of assessment in the prison) may have resulted in socially desirable reporting that, in turn, may have interfered in the accuracy of the results (Proulx \& Sauvêtre, 2007). It is also of note that the studies from Canada used the Ressler et al. (1988) definition of sexual homicide, while studies from the UK tended to use cases of murder or manslaughter where a sexual element and/ or a sexual motivation was evidenced, suspected or admitted; a definition now used nationwide by the NOMS.

Following the inclusion/exclusion criteria, studies examining serial killers were not included, although when the sample was non-serial but included few cases of serial killers the studies were retained (e.g. Grubin, 1994; Healey et al., 2013). In a similar fashion, studies where the perpetrators offended predominantly against pubescent female victims were included (e.g. Milsom et al., 2003; Oliver et al., 2007) (see Table 1 for full details of the sample structure).

The majority of studies used a combination of official records, standardised tools and interviews when comparing the samples. Overall, sexual killers and sexual aggressors were compared in relation to: various demographic and offender characteristics (Grubin, 1994; Milsom et al., 2003; Oliver et al., 2007; Vettor et al., 2014); developmental and family structure (Grubin, 1994; Milsom et al., 2003; Nicole \& Proulx, 2007; Oliver et al., 2007; Vettor et al., 2014); criminal history (Grubin, 1994; Milsom et al., 2003; Nicole \& Proulx, 2007; Oliver et al., 2007; Vettor et al., 2014); mental health and personality disorders (Grubin, 1994; Oliver et al., 2007; Proulx \& Sauvêtre, 2007; Vettor et al., 2014) and crime characteristics (Chéné \& Cusson, 2007; Healey et al., 2013; Higgs et al., 2015; Salfati \& Taylor, 2006) (see Table 1 for full details of these demographics).

\section{Descriptive data synthesis}

The data were synthesised and thematically arranged into categories of information (Braun \& Clarke, 2006). The key differences and similarities identified from the results of all 10 studies were searched for the recurrent themes (i.e. homogeneous or heterogeneous characteristics). A theme was established if a given characteristic was reported in the results section of at least three different studies. Applying such an approach was deemed appropriate given that thematic analysis is flexible since it is not linked to any theoretical position. This allows patterns in the data to be identified without the need for full theoretical analysis (Atkinson \& Mann, 2012). Overall, 15 themes were established (Table 2). 


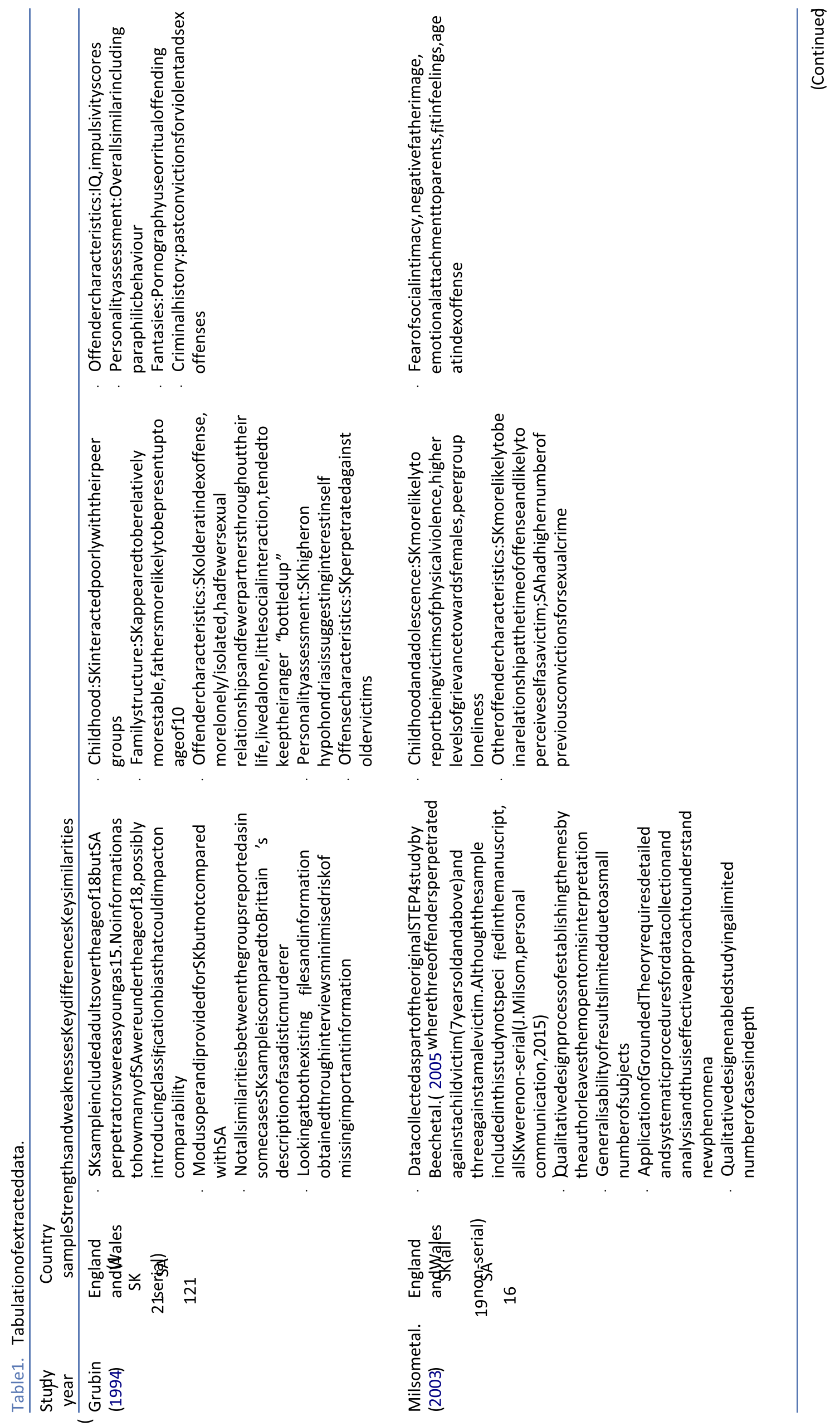




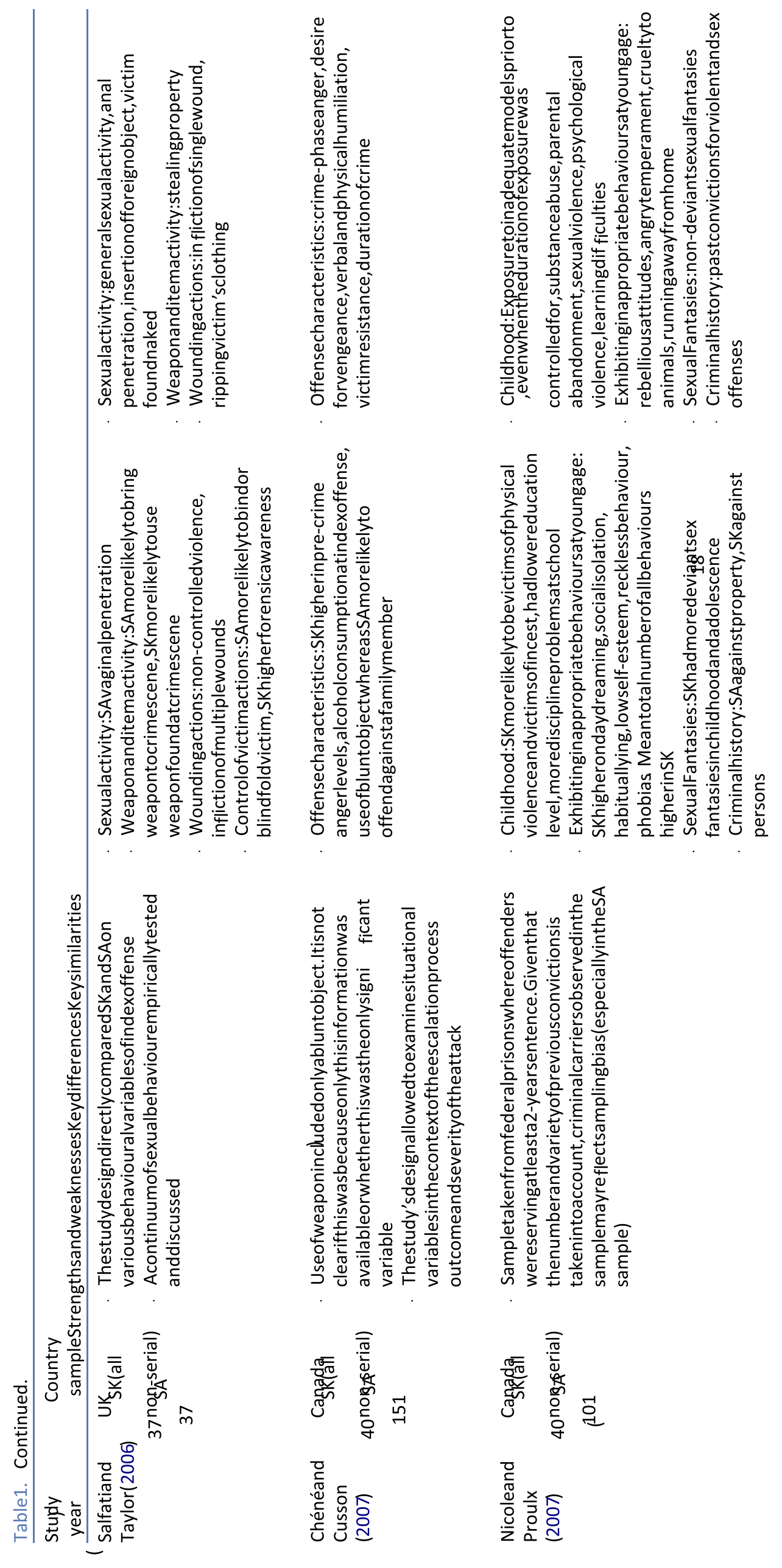



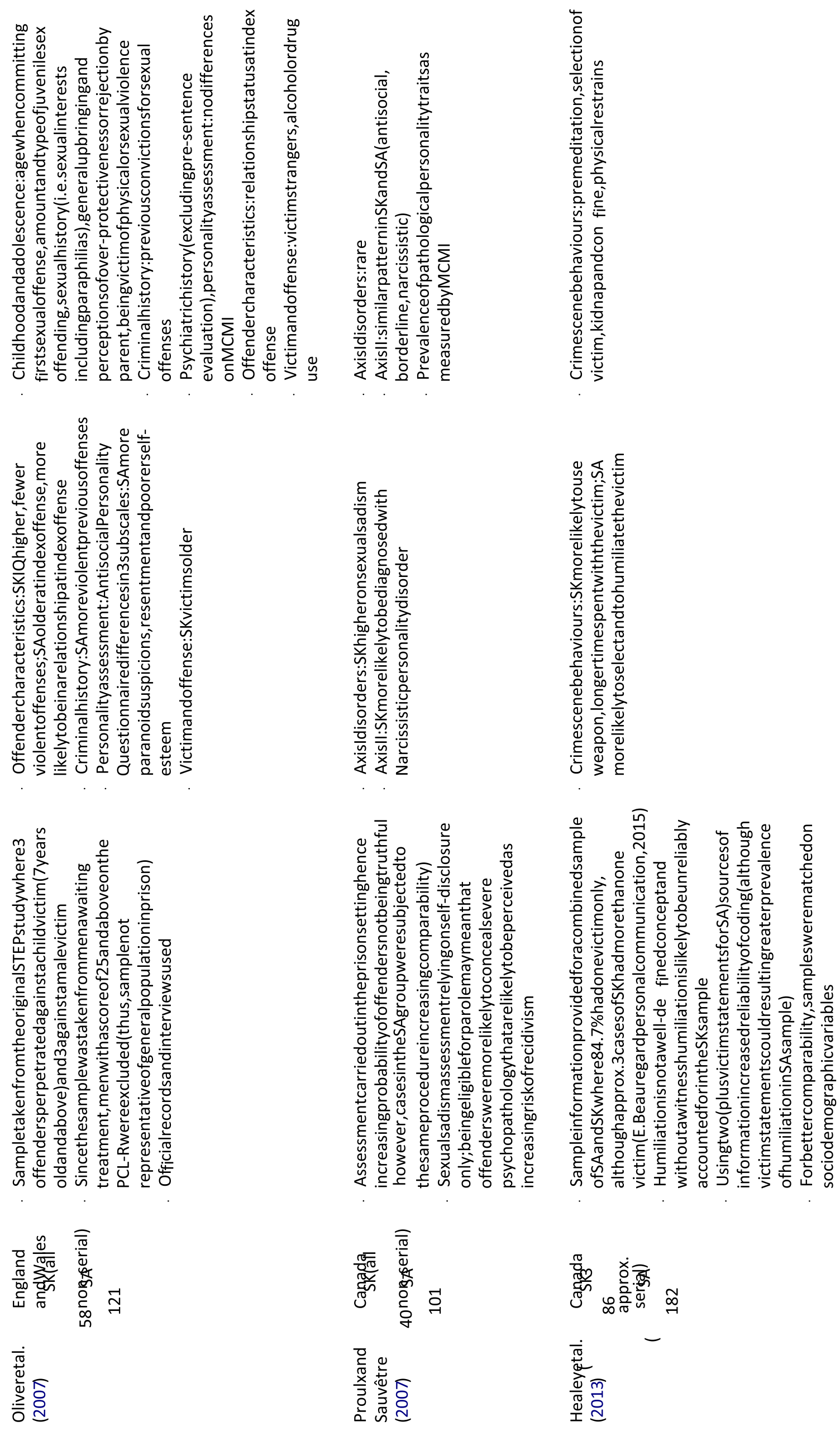


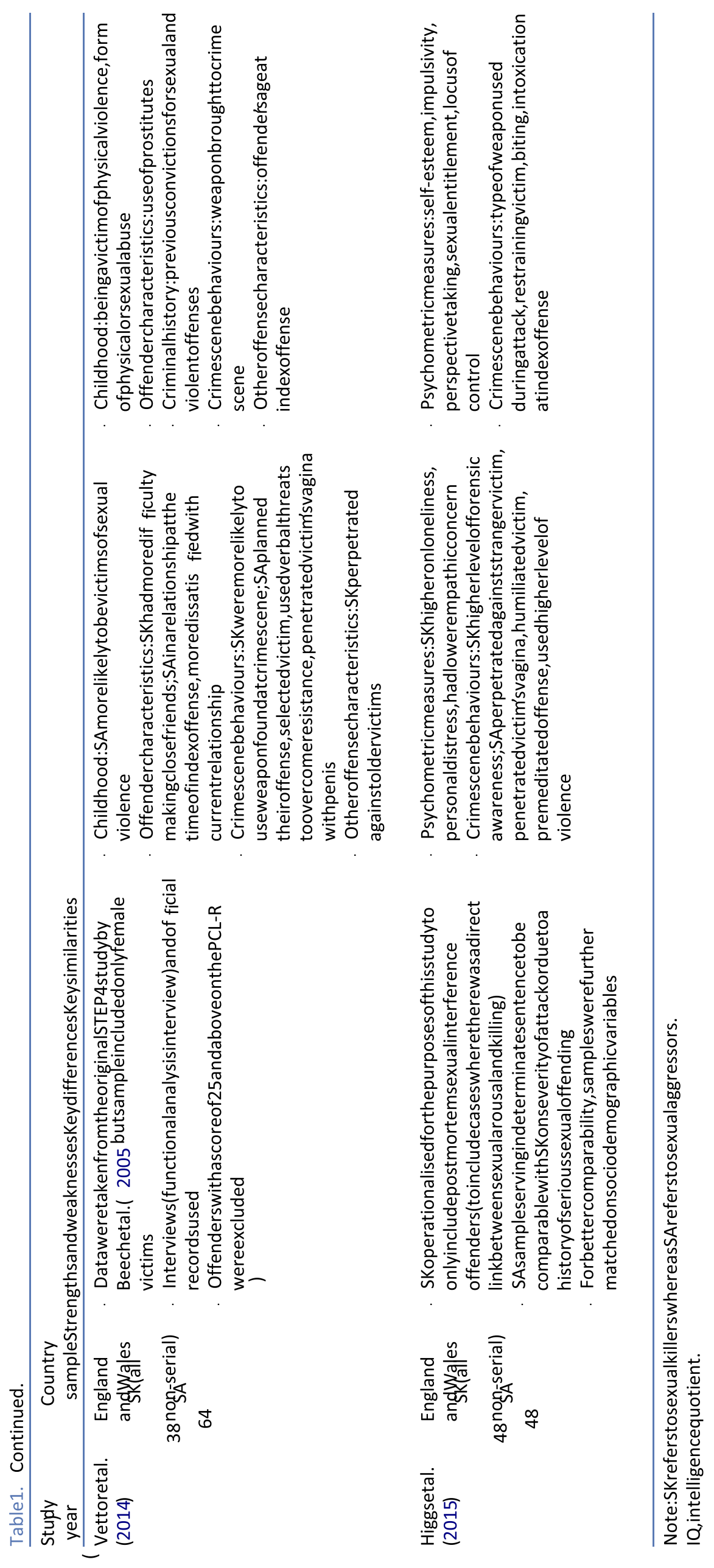


Table 2. Data synthesis.

\begin{tabular}{|c|c|c|c|c|}
\hline Theme & SK higher & SA higher & No difference noted & Result \\
\hline $\begin{array}{l}\text { Offender characteristics } \\
\text { Loneliness }\end{array}$ & $\begin{array}{l}\text { Grubin (1994) } \\
\text { Milsom et al. (2003) } \\
\text {. Nicole and Proulx } \\
\text { (2007) } \\
\text {. Higgs et al. (2015) }\end{array}$ & & & $\begin{array}{l}\text { Appears } \\
\text { different }\end{array}$ \\
\hline Anger & $\begin{array}{l}\text { Chéné and Cusson } \\
\text { (2007) } \\
\text { Grubin (1994) }\end{array}$ & & Vettor et al. (2014) & $\begin{array}{l}\text { Possibly } \\
\text { different }\end{array}$ \\
\hline Mental disorders & & & $\begin{array}{l}\text { Grubin (1994) } \\
\text { Oliver et al. (2007) } \\
\text { Proulx and Sauvêtre } \\
(2007)\end{array}$ & $\begin{array}{l}\text { Appears } \\
\text { similar }\end{array}$ \\
\hline $\begin{array}{l}\text { Criminal history } \\
\text { (sex offenses) }\end{array}$ & & $\begin{array}{l}\text { Milsom et al. } \\
\text { (2003) }\end{array}$ & $\begin{array}{l}\text { Grubin (1994) } \\
\text { Nicole and Proulx } \\
\text { (2007) } \\
\text { Oliver et al. (2007) } \\
\text { Vettor et al. (2014) }\end{array}$ & $\begin{array}{l}\text { Appears } \\
\text { similar }\end{array}$ \\
\hline $\begin{array}{l}\text { Criminal history } \\
\text { (violent offenses) }\end{array}$ & & · Oliver et al. (2007) & $\begin{array}{l}\text { Grubin (1994) } \\
\text { Milsom et al. (2003) } \\
\text { Nicole and Proulx } \\
\text { (2007) } \\
\text {. Vettor et al. (2014) }\end{array}$ & $\begin{array}{l}\text { Appears } \\
\text { similar }\end{array}$ \\
\hline Family structure & Grubin (1994) & & $\begin{array}{l}\text { Nicole and Proulx } \\
\text {.. (2007) } \\
\text { Oliver et al. (2007) }\end{array}$ & $\begin{array}{l}\text { Possibly } \\
\text { similar }\end{array}$ \\
\hline $\begin{array}{l}\text { Own victimisation } \\
\text { (sexual) }\end{array}$ & & . Vettor et al. (2014) & $\begin{array}{l}\text { Grubin (1994) } \\
\text { Nicole and Proulx } \\
\text { (2007) } \\
\text { Oliver et al. (2007) }\end{array}$ & $\begin{array}{l}\text { Possibly } \\
\text { similar }\end{array}$ \\
\hline Own victimisation (physical) & $\begin{array}{l}\text { Milsom et al. (2003) } \\
\text { Nicole and Proulx } \\
\text { (2007) }\end{array}$ & & $\begin{array}{l}\text { Grubin (1994) } \\
\text { Oliver et al. (2007) } \\
\text { Vettor et al. (2014) }\end{array}$ & Inconclusive \\
\hline $\begin{array}{l}\text { Relationship status at the time of } \\
\text { offense }\end{array}$ & Milsom et al. (2003) & $\begin{array}{l}\text { Oliver et al. (2007) } \\
\text { Vettor et al. (2014) }\end{array}$ & & Inconclusive \\
\hline Low self-esteem & $\begin{array}{l}\text { Nicole and Proulx } \\
\text { (2007) }\end{array}$ & . Oliver et al. (2007) & · Higgs et al. (2015) & Inconclusive \\
\hline Age at index offense & . Grubin (1994) & · Oliver et al. (2007) & $\begin{array}{l}\text { Milsom et al. (2003) } \\
. \text { Vettor et al. (2014) }\end{array}$ & Inconclusive \\
\hline
\end{tabular}


Table 2. Continued.

\begin{tabular}{|c|c|c|c|c|}
\hline Theme & SK higher & SA higher & No difference noted & Result \\
\hline Premeditation & & $\begin{array}{l}\text { Salfati and Taylor } \\
(2006) \\
\text { Vettor et al. (2014) } \\
\text { Higgs et al. (2015) }\end{array}$ & . Healey et al. (2013) & $\begin{array}{l}\text { Possibly } \\
\text { different }\end{array}$ \\
\hline Humiliation & & $\begin{array}{l}\text { Healey et al. (2013) } \\
\text { Higgs et al. (2015) }\end{array}$ & $\begin{array}{l}\text { Chéné and Cusson } \\
\text { (2007) }\end{array}$ & $\begin{array}{l}\text { Possibly } \\
\text { different }\end{array}$ \\
\hline Victim restrained & Vettor et al. (2014) & $\begin{array}{l}\text { Salfati and Taylor } \\
\text { (2006) }\end{array}$ & $\begin{array}{l}\text { Healey et al. (2013) } \\
\text {. Higgs et al. (2015) }\end{array}$ & Inconclusive \\
\hline
\end{tabular}

Note: SK refers to sexual killers whereas SA refers to sexual aggressors.

\section{Heterogeneous offender characteristics Loneliness}

Grubin (1994) reported that the factors distinguishing sexual aggressors from sexual killers were mainly related to the increased likelihood of loneliness and social isolation in the latter. In childhood, sexual killers tended to interact poorly with their peers $(p<.01)$, they had fewer relationships throughout their lives $(p<.0001)$, were more likely to live alone $(p<.05)$ and less likely to live with a partner in the year of the offence $(p<.01)$. Eighty-six per cent of sexual killers had at least one feature suggesting social isolation, compared to $45 \%$ of the sexual aggressor sample $(p<.001)$. Milsom et al. $(2003)$ found that peer group loneliness in adolescence was significantly more prevalent in sexual killers $(p<.05)$. In line with these findings, Nicole and Proulx (2007) noted significantly higher levels of social isolation in adulthood among sexual killers ( $p<.05$ ). However, while Milsom et al. (2003) did not find any differences on self-reported psychometric data on emotional loneliness, Higgs et al. (2015) found that sexual killers' emotional loneliness scores were higher than sexual aggressors' $(p<.01)$, with a large effect size in the difference in these scores (eta squared $=.14$ ). Overall, these data suggest that loneliness and social isolation are distinctive features of sexual killers, but it is difficult to establish whether loneliness in adolescence or in adulthood is more prevalent. This should be the focus in future studies.

\section{Anger}

Chéné and Cusson (2007) noted that crime-phase anger did not predict the outcome of the assault but when the assailant was angry before the crime (pre-crime stage) the attack was more likely to end in murder $(p<.05)$. Grubin (1994) also found that sexual killers were more likely to keep their anger "bottled up" suggesting the presence of pre-crime-phase anger $(p<.05)$. In contrast, Vettor et al. (2014) reported that sexual killers' feelings of anger did not differ from those of sexual aggressors. However, both Chéné and Cusson (2007) and Vettor et al. (2014) do not specify the possible length (hours or days) of the pre-crime stage. While for Chéné and Cusson (2007) this phase was operationalised as "prior to crime" (p. 85), in Vettor et al. (2014) study pre-crime meant "just prior to offense" (p. 296). 
Due to these unclear coding criteria although anger possibly distinguishes sexual killers from sexual aggressors, this factor would benefit from further examination.

\section{Homogeneous offender characteristics Mental disorders}

After excluding pre-sentence evaluation, Oliver et al. (2007) noted that $68 \%$ of sexual killers and $48 \%$ of sexual aggressors had had "some sort of psychiatric assessment or intervention" (p. 168). The differences in psychiatric history were not significant although outcomes of assessment were not considered in the analysis and the results should therefore be interpreted with caution. Grubin (1994) also did not find any differences in previous psychiatric contact between the groups. Finally, Proulx and Sauvêtre (2007) noted low prevalence rates of clinically diagnosed axis I disorders of the Diagnostic and statistical manual of mental disorders 4th edition (American Psychiatric Association, 2000), including low prevalence rates of sexual sadism. However, in most studies, samples were taken from the prison population, which inevitably means that offenders were found responsible for their crimes leading to a possible underrepresentation of mental disorders.

\section{Criminal history}

Grubin (1994), Nicole and Proulx (2007) and Vettor et al. (2014) did not find any differences between the groups in terms of prevalence rates for previous convictions for sexual as well as violent offences. Grubin (1994) noted that, although the groups were similar, sexual killers had a higher number of past convictions for rape. While the sample in the Milsom et al. (2003) study revealed that the groups did not differ in the prevalence rates of previous violent offences, sexual aggressors were significantly more likely to have a previous conviction for a sexual crime $(p<.05)$. On the other hand, the Oliver et al. (2007) study showed no differences in terms of previous sexual convictions but sexual aggressors had significantly more convictions for violent crimes ( $p$.05). In addition, Nicole and Proulx (2007) observed that, although not significantly different, the criminal careers of sexual aggressors were more oriented towards property whereas the criminal records of sexual killers encompassed more violence towards persons. The results should also be interpreted with caution as the sample was taken from federal prisons, which means that the subjects were serving sentences of at least two years. Given that the number and variety of previous convictions were taken into account, criminal careers observed in the sample may simply reflect sampling bias. This should not affect the sexual killers group as they receive statutory life sentences. However, broadly, the sexual killer and sexual aggressor groups appear similar in terms of previous convictions

\section{Family structure}

Grubin (1994) found that the family structure of sexual killers tended to be more stable. Specifically, individuals in this group experienced less domestic change $(p<.05)$ with fathers who were more likely to be present in the first 10 years of their lives $(p<.05)$ and who were rated as more stable based on factors such as criminal history, unemployment and alcoholism $(p<.05)$. Oliver et al. (2007) reported no differences as individuals in both groups tended to perceive their relationship with their parents in a similar way although, due to the design of the questionnaire, a distinction between mother and father could not be made as most offenders rated their parents together. Nicole and Proulx (2007) also reported no differences between the groups in their exposure to inadequate parenting prior to the age of 18. This category included exposure to abusive alcohol consumption, psychological violence and witnessing physical violence but excluded own victimisation. The groups appeared similar even when the scores on a global, duration-weighted scale (that takes into account the duration of the exposure) were calculated. 
Own victimisation (sexual)

In Vettor et al. (2014) sexual aggressors were significantly more likely to report suffering sexual abuse as a child. In contrast to this finding, Grubin (1994) and Oliver et al. (2007) reported that sexual killers and sexual aggressors did not differ in their reports of childhood sexual victimisation. Although the groups were similar, Oliver et al. (2007) noted that the prevalence rates were high as over half of their sample reported experiencing sexual abuse, generally from a male perpetrator who was a family friend or acquaintance. Exposure to sexual violence was also not significantly different in Nicole and Proulx (2007) study but sexual killers were significantly more likely to report having been victims of incest ( $p$ $<.01)$.

Inconclusive offender characteristics Own victimisation (physical)

Grubin (1994), Oliver et al. (2007) and Vettor et al. (2014) found no differences in childhood physical victimisation between their sexual killers and sexual aggressors groups. In contrast to this finding, both Milsom et al. (2003) and Nicole and Proulx (2007) noted that sexual killers were more likely to experience physical abuse (68\% vs. $13 \%, p>.01$ and $64.1 \%$ vs. $41.6 \%, p<.05$, respectively), although it should be noted that the Milsom et al. (2003) study only involved a small sample size $(N=19)$. The use of physical violence could be explained by Bandura's (1977) model of social learning, in that excessive force could end in murder. However, given the inconclusive results from the studies, it was not possible to determine whether this factor is heterogeneous or homogeneous in nature.

\section{Relationship status at the time of offence}

Milsom et al. (2003) noted that sexual killers were more likely to be in a relationship at the time of offence $(p<.05)$. This was in contrast to Oliver et al. (2007) and Vettor et al. (2014) which indicated sexual aggressors being more likely to be married or having one main partner $(p<.01$ and $p<.05$, respectively). However, given the considerable overlap of samples in all three studies, the results were deemed inconclusive.

\section{Low self-esteem}

Nicole and Proulx (2007) found sexual killers showed higher prevalence of low self-esteem where Oliver et al. (2007) found this to be true for their sexual aggressors sample. In Higgs et al. (2015) study the difference between the groups was not significant. Nicole and Proulx (2007) referred to self-esteem in adolescence. Oliver et al. (2007) and Higgs et al. (2015) used psychometric data on current self-esteem, although the scales used were different.

\section{Age at index offence}

In Grubin's (1994) sample, at the time of the relevant offence, sexual killers were significantly older than sexual aggressors. In contrast, the sexual killers in the Oliver et al. (2007) study sample were significantly younger. Both Vettor et al. (2014) and Milsom et al. (2003) did not find any differences in the mean age when the crime was committed. The results therefore remain inconclusive.

\section{Heterogeneous crime scene behaviours Sexual activity}

Three studies (Higgs et al., 2015; Salfati \& Taylor, 2006; Vettor et al., 2014) examined sexual activity as a variable. All these studies reported that sexual aggressors forced vaginal penetration with higher frequency than sexual killers (who were more likely to also force anal penetration, use object insertion or sexually position the body). This was significant at $p<.01, p<.001$ and $p<.01$, respectively. These results might not be surprising given that by definition sexual aggression would include cases of unlawful penetration whereas sexual killing would include cases where there were any physical signs of a sexual character indicating a sexual motive. For example, when the body was found naked or the attack included mutilation of sexual body parts. 


\section{Premeditation}

While in the study by Healey et al. (2013) premeditation was not a significant discriminator of sexual killing or sexual aggression, both Vettor et al. (2014) and Higgs et al. (2015) noted that sexual aggressors were significantly more likely to premeditate their crime. Although Salfati and Taylor (2006) did not look at premeditation per se, they reported that sexual aggressors more frequently brought a weapon to the crime scene. In the study by Higgs et al. (2015), taking a weapon was counted as an indicator of planning. Even though Vettor et al. (2014) did not specify the way they had operationalised premeditation, the authors noted that "sexual murderers typically used a weapon they had found at the scene, which again indicates a more spontaneous offense" (p. 300). Taking a weapon to the crime scene is not a highly reliable indicator of planning which may result in underestimation of premeditation for sexual killers. Even when other behavioural factors (e.g. taking a rape kit or targeting victim) are taken into consideration, the question of whether the perpetrator planned the killing or a sexual assault remains unanswered. Indeed, Stefanska et al. (2015) found that deviance driven perpetrators for whom violence and killing create sexual arousal were just as likely to premeditate their offences as the perpetrators who were more aligned to rapists in that their primary objective was to gain sexual gratification but killed for instrumental reasons either to silence the victim or to avoid detection.

\section{Humiliation}

Chéné and Cusson (2007) found that verbal and physical humiliation was not significantly associated with the outcome of the offence. On the other hand, Healey et al. (2013) and Higgs et al. (2015) reported that in their samples, sexual aggressors tended to display higher levels of humiliation. Attention should be drawn to the fact that even though data are generally collected from an extensive database in case of sexual killers, and contrary to sexual aggressors, witness statements are not available. Without witness statements, humiliation is likely to be unreliably accounted for leading to a likely underestimation of its occurrence in sexual killings.

\section{Inconclusive crime scene behaviours Victim restrained}

Vettor et al. (2014) found that acts of restraining a victim were evident more frequently in sexual killers. Contrarily, Salfati and Taylor (2006) noted this pattern more frequently in sexual aggressors. In both Healey, Beauregard, Beech, and Vettor's (2014) and Higgs et al.'s (2015) studies the use of physical restraints was relatively uncommon and did not discriminate sexual killers from sexual aggressors, leaving the results inconclusive.

\section{Discussion}

This review has been carried out in order to advance our understanding of what is known about the characteristics of sexual killers and sexual aggressors. Conclusions can be drawn from this review as to what characteristics have consistently been shown to be homogeneous (i.e. reported across both perpetrator groups) and which appear to be heterogeneous (i.e. more prevalent to one of the groups). The review systematically looked at the studies where the samples of sexual killers were male, predominantly non-serial, perpetrating against predominantly adult female victims and where the groups were directly compared. Following the systematic process, a total of 825 articles were identified although these were condensed to 10 studies after duplicates were removed and inclusion and exclusion criteria were applied.

When looking at offender characteristics, the results indicate that loneliness and anger appear to be heterogeneous (i.e. different and more prevalent for one group) characteristics whereas mental health disorders, perpetrator criminal history (sexual and violent), family structure and history of sexual abuse seem to be homogeneous (i.e. similar across two groups) characteristics. It should be noted that it was 
not possible to establish whether loneliness in adolescence or in adulthood was more prevalent and anger appeared to be relating to a pre-crime phase. When looking at crime scene behaviours, sexual activity (vaginal penetration), premeditation and humiliation appeared to be heterogeneous characteristics. The results of the remaining five themes (i.e. relationship status at the time of offence, perpetrator physical victimisation, low self-esteem, age at index offence and restraining victim during commissioning of crime) are contradictory and thus a firm conclusion about their relevance (about their affiliation) cannot be reached. The results support some of the results obtained by Carter and Hollin (2010), who also reviewed characteristics of non-serial sexual killers, and who found that individuals in this group were socially isolated and angry before the offence. However, as Carter and Hollin (2010) aimed to identify possible characteristics prevalent in individuals convicted of sexual murder, they did not report homogeneous characteristics of sexual killers and sexual aggressors. Thus, similarities between the groups found in this review could not be compared to the review by Carter and Hollin.

From a theoretical standpoint, high levels of anger and social isolation reported in sexual killers should not surprising. Although research suggests that anger is an important antecedent to sexual offending in general, sexual killers in particular (especially those following the anger driven pathway) tend to be over-controlling and the killing is seen as a sudden release of the intense levels of the bottled-up emotions (Grubin, 1994; Kerr et al., 2013). Indeed, within such context the offences are more likely to be triggered by something that a victim said or did: for example, after an argument, a failed erection, or when the victim refused further sexual advances (Stefanska et al., 2015). This perhaps explains the more frequent evidence of "overkill" suggestive of a frenzied attack (e.g. Beauregard \& Proulx 2002; Stefanska et al., 2015). Emotional loneliness can add to an increase in feelings of frustration, and in an unskilled and isolated individual may lead to daydreaming that with time (and often in the presence of various disinhibiting factors such as pornography) may develop into deviant sexual interests and sadistic fantasies (Nicole \& Proulx, 2007). For those perpetrators (especially following the sadistic pathway) the offence is a culmination of such interests which are often reflected in a more frequent evidence of ritualised behaviours (e.g. Beauregard \& Proulx 2002; Stefanska et al., 2015). However, it should be highlighted that these are only few noteworthy considerations as an in depth discussion of the predisposing factors is beyond the scope of this paper.

Furthermore, this review has highlighted some methodological problems of the studies included. Amongst the most common were: difficulties with availability of different sources of information (e.g. Healey et al., 2013; Higgs et al., 2015); the source of data creating sampling bias (e.g. Nicole \& Proulx, 2007) or resulting in exclusion of some offenders from the samples (e.g. Oliver et al., 2007; Vettor et al., 2014); the need of relying on self-disclosure (e.g. Proulx \& Sauvêtre, 2007); differences when using clinical judgment or psychometric assessments as their data source (Proulx \& Sauvêtre, 2007) or relying on evidence in proxy when coding some items (e.g. Healey et al., 2013; Higgs et al., 2015). These problems may be expected given the main methodological complications encountered by researchers within the wider research literature on sexual killing, that is, the low prevalence rates and the difficulties in accessing detailed descriptions of the offence, which inevitably mean that small sample sizes are used in the studies. Although most researchers aimed to overcome some of these difficulties either by using a variety of data sources in order to increase reliability of coding (e.g. Grubin, 1994; Oliver et al., 2007) or by further matching samples in order to increase comparability (e.g. Healey et al., 2013; Higgs et al., 2015), a process of data extraction enabled this review to establish that, in all of 10 studies, approximately 300 sexual killers were actually compared in total.

Perhaps the most surprising result of the review is that out of the 10 studies that tended to examine a wide array of variables, only 15 themes could be established (on the basis that a given characteristic was reported in the results section of at least three different studies). Noting this small number of identifiable themes is important in light of the fact that a number of researchers reached a general conclusion that there are more similarities than differences between the groups. Some researchers have subsequently proposed that sexual aggression and sexual killing should best be conceptualised as occurring along a single continuum of sexual offending with the level of circumstantial violence being 
the critical discriminator of whether or not the outcome is fatal (Oliver et al., 2007; Proulx et al., 2007; Salfati \& Taylor, 2006).

As the comparison studies encompassed all sexual killers in a single group, they ignored the reasonably well established types of the sexual killer and the different, direct (sexual aspect of the offence can be demonstrably connected to death) and indirect (killing is not a source of sexual stimulation but only occurs in the sexual context) roles that killing can play in relation to sexual behaviour.

Specifically, it has been noted that for some offenders although a homicide occurred within a sexual context, it is not known whether these offenders may be as likely to kill in a non-sexual situation. Particularly those driven to kill due to grievance thinking with no sexual motivation and only indirect link between sex and killing should be considered for comparison to non-sexual homicide in the future (Carter, Hollin, Stefanska, \& Higgs, 2015). On the other hand, perpetrators with an indirect link between sex and killing who were sexually motivated to offend but killed either to avoid detection or in the context of the victim-aggressor dynamic (i.e. victim was killed trying to escape the sexual assault) may well be more akin to non-homicide sexual aggressors (Stefanska et al., 2015). Although omitting typology when comparing sexual killers with sexual aggressors is perhaps inevitable in many studies due to the aforementioned inherent limitations of the data, when operationalising sexual killing it should not be forgotten that the selection criteria for studies can, and most likely do, affect the conclusions drawn.

\section{Limitations}

The strength of this review lies in the fact that it has only considered studies that directly compared sexual killers with sexual aggressors and excluded those where sexual killers and sexual aggressors were examined in isolation. This design allowed both the sample selection and classification bias to be minimised thereby increasing comparability. This review has also examined the methodological problems of the studies included in an attempt to explain some of the problems in the results obtained by different researchers. Analysing data thematically has further allowed patterns in the data to be identified without the need for full theoretical analysis.

However, because the review excluded studies looking at sexual killers in isolation, only 10 studies were included. While it could be argued that this is a true representation of the current state of knowledge in regards to comparison of sexual killers to sexual aggressors, the studies included were only from the UK and Canada, which affects the generalisability of the results. In addition, many studies from the USA were excluded either because of their tendency to look at serial sexual killers in isolation or because of the overrepresentation of the serial compared to non-serial offenders in their samples. Studies that had not been translated to English were also excluded. The final criticism might be that, although the search strategy appears comprehensive, it is possible that the use of different key terms would have resulted in a broader search scope and more numerous results.

\section{Conclusions}

The findings of this review should improve the understanding of what is known about the characteristics of sexual killers and sexual aggressors. The results showed that some characteristics (such as loneliness and anger) are heterogeneous characteristics (i.e. different and more prevalent for one group) whereas others (such mental health disorders, criminal history, family structure and history of sexual abuse as well as some crime scene behaviours including sexual activity, premeditation and humiliation) are homogeneous characteristics (i.e. similar across the two groups). Conclusions about some of the characteristics could not be made because of inconclusive results. Nevertheless, regardless of whether correlations can be established, this review has demonstrated that many factors would 
benefit from more research and that these points should be the focus of further study. Improving understanding of the similarities and differences between the groups is important from the perspective of offender treatment and management but also, as discussed above, from the perspective of future research.

\section{Disclosure statement}

No potential conflict of interest was reported by the authors.

\section{References}

American Psychiatric Association. (2000). Diagnostic and statistical manual of mental disorders (4th ed., text revision). Washington, DC: Author.

Atkinson, D. F., \& Mann, R. E. (2012). Prison officers as observers of offence paralleling behaviours: An untapped resource? Journal of Forensic Psychiatry and Psychology, 23, 139-155. doi:10.1080/14789949.2012.668209 Bandura, A. (1977). Social learning theory. Englewood Cliffs, NJ: Prentice Hall.

Beauregard, E., \& Proulx, J. (2002). Profiles in the offending process of non-serial sexual murderers. International Journal of Offender Therapy and Comparative Criminology, 51, 420-432. doi:10.1177/0306624X02464002.

Beech, A. R., Fisher, D., \& Ward, T. (2005). Sexual murderers' implicit theories. Journal of Interpersonal Violence, 20, 13361389. doi:10.1177/0886260505278712

Braun, V., \& Clarke, V. (2006). Using thematic analysis in psychology. Qualitative Research in Psychology, 3, 77-101. doi:10. 1191/1478088706qp063oa

Campos, E., \& Cusson, M. (2007). Serial killers and sexual murderers. In J. Proulx, E. Beauregard, M. Cusson, \& A. Nicole (Eds.), Sexual murderers: A comparative analysis and new perspectives (pp. 100-105). Chichester, UK: John Wiley.

Carter, A. J., \& Hollin, C. R. (2010). Characteristics of non-serial sexual homicide offenders: A review. Psychology, Crime and Law, 16, 25-45. doi:10.1080/10683160802621933

Carter, A. J., Hollin, C. R., Stefanska, E. B., \& Higgs, T. (2015). The use of crime scene and demographic information in the identification of non-serial sexual killers (manuscript submitted for publication).

Chan, H. C., \& Heide, K. (2009). Sexual homicide: A synthesis of the literature. Trauma, Violence and Abuse, 10, 31-54. doi:10.1177/1524838008326478

Chéné, S., \& Cusson, M. (2007). Sexual murderers and sexual aggressors: Intention and situation. In J. Proulx, E. Beauregard, M. Cusson, \& A. Nicole (Eds.), Sexual murderers: A comparative analysis and new perspectives (pp. 70-86). Chichester: John Wiley \& Sons Ltd.

Cusson, M., \& Proulx, J. (2007). The motivation and criminal career of sexual murderers. In J. Proulx, E. Beauregard, M. Cusson, \& A. Nicole (Eds.), Sexual murderers: A comparative analysis and new perspectives (pp. 142-155). Chichester: John Wiley \& Sons Ltd.

Folino, J. O. (2000). Sexual homicides and their classification according to motivation: A report from Argentina. International Journal of Offender Therapy and Comparative Criminology, 44, 740-750. doi:10.1177/0306624X00446009

Grubin, D. (1994). Sexual murder. British Journal of Psychiatry, 165, 624-629.

Healey, J., Lussier, P., \& Beauregard, E. (2013). Sexual sadism in the context of rape and sexual homicide: An examination of crime scene indicators. International Journal of Offender Therapy and Comparative Criminology, 57, 402-424. doi:10. $1177 / 0306624 \times 12437536$

Healey, J., Beauregard, E., Beech, A., \& Vettor, S. (2014). Is the sexual murderer a unique type of offender? A typology of violent offenders using crime scene behaviors. Sexual Abuse: A Journal of Research and Treatment, Advance online publication. doi:10.1177/1079063214547583

Higgs, T., Carter, A. J., Stefanska, E. B., \& Glorney, E. (2015). Towards identification of the sexual killer: A comparison of sexual killers engaging in post mortem sexual interference and non-homicide sexual aggressors. Sexual Abuse: A Journal of Research and Treatment. Advance online publication. doi:10.1177/1079063215609935

James, J., \& Proulx, J. (2014). A psychological and developmental profile of sexual murderers: A systematic review. Aggression and Violent Behavior, 19, 592-607. doi:10.1016/j.avb.2014.08.003

Kerr, K. J., Beech, A. R., \& Murphy, D. (2013). Sexual homicide: Definition, motivation and comparison with other forms of sexual offending. Aggression and Violent Behavior, 18, 1-10. doi:10.1016/j.avb.2012.05.006

Kopec J. A., \& Esdaile, J. M. (1990). Bias in case-control studies. A review. Journal of Epidemiology and Community Health, 44, 179-186. doi:10.1136/jech.44.3.179

Langevin, R., Ben-Aron, M. H., Wright, P., Marchese, V., \& Handy, L. (1988). The sex killer. Annals of Sex Research, 1, 263302. doi:10.1177/107906328800100206

Maniglio, R. (2010). The role of deviant sexual fantasy in the etiopathogenesis of sexual homicide: A systematic review. Aggression and Violent Behavior, 15, 294-302. doi:10.1016/j.avb.2010.02.001 
Milsom, J., Beech, A. R., \& Webster, S. D. (2003). Emotional loneliness in sexual murderers: A qualitative analysis. Sexual Abuse: A Journal of Research and Treatment, 15, 285-296. doi:10.1023/A:1025095927047

National Health Service. (2013). Critical appraisal skills program (CASP). Retrieved September 2014, from http://www.caspuk.net/

Nicole, A., \& Proulx, J. (2007). Sexual murderers and sexual aggressors: Developmental paths and criminal history. In J. Proulx, E. Beauregard, M. Cusson, \& A. Nicole (Eds.), Sexual murderers: A comparative analysis and new perspectives (pp. 5169). Chichester: John Wiley \& Sons.

Oliver, C. J., Beech, A. R., Fisher, D., \& Beckett, R. (2007). A comparison of rapists and sexual murderers on demographic and selected psychometric measures. In J. Proulx, E. Beauregard, M. Cusson, \& A. Nicole (Eds.), Sexual murderers: A comparative analysis and new perspectives (pp. 70-86). Chichester: John Wiley \& Sons.

Porter, S., Woodworth, M., Earle, J., Drugge, J., \& Boer, D. (2003). Characteristics of sexual homicides committed by psychopathic and non-psychopathic offenders. Law and Human Behavior, 27, 459-469. doi:10.1023/A:10254614 21791

Pretticrew, M., \& Roberts, H. (2006). Systematic reviews in social sciences: A practical guide. Malden, MA: Blackwell Publishing.

Proulx, J. (2008). Sexual murderers: Theories, assessment and treatment. In A. J. R. Harris \& C. A. Pagé (Eds.), Sexual homicide and paraphilias: The Correctional service of Canada's experts forum 2007 (pp. 215-233). ON: Correctional Service of Canada.

Proulx, J., Cusson, M., \& Beauregard, E. (2007). Sexual murderer: Definitions, epidemiology and theories. In J. Proulx, E. Beauregard, M. Cusson, \& A. Nicole (Eds.), Sexual murderers: A comparative analysis and new perspectives (pp. 51- 69). Chichester: John Wiley \& Sons.

Proulx, J., \& Sauvêtre, N. (2007). Sexual murderers and sexual aggressors: Psychopathological considerations. In J. Proulx, E. Beauregard, M. Cusson, \& A. Nicole (Eds.), Sexual murderers: A comparative analysis and new perspectives (pp. 51-69). Chichester: John Wiley \& Sons.

Ressler, R. K., Burgess, A. W., \& Douglas. (1988). Sexual homicide: Patterns and motives. New York, NY: Lexington.

Roberts, J. V., \& Grossman, M. G. (1993). Sexual homicide in Canada: A descriptive analysis. Annals of Sex Research, 6, 5-25. doi:10.1007/BF00849743

Salfati, G., \& Taylor, P. (2006). Differentiating sexual violence: A comparison of sexual homicide and rape. Psychology, Crime and Law, 12, 107-125. doi:10.1080/10683160500036871

Schlesinger, L. B. (2004). Sexual murder: Catathymic and compulsive homicides. Boca Raton, FL: CRC Press.

Stefanska, E. B., Carter, A. J., Higgs, T., Bishopp, D., \& Beech, A. R. (2015). Offence pathways to non-serial sexual killers. Journal of Criminal Justice, 43, 99-107.

Vettor, S., Beech, A. R., \& Woodham, J. (2014). Rapists and sexual murderers: Combined pathways to offending. In J. Proulx (Eds.), Pathways to sexual offending (pp. 285-315). Abingdon: Routledge. 